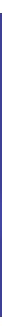

\title{
EDUCAÇÃO SEXUAL E SEXUALIDADES: REFLEXÕES SOBRE AÇÕES EXTENSIONISTAS NA FORMAÇÃO DE PROFESSORES/AS
}

\author{
Joseval dos Reis Miranda \\ Universidade Federal da Paraíba \\ josevalmiranda@yahoo.com.br
}

Resumo

Este relato de experiência discorre sobre o projeto de extensão "Educação sexual: prazer em conhecer", desenvolvido durante o ano letivo de 2013 e início de 2014, na área temática da educação, discutindo especificamente a formação de professores sobre questões da sexualidade e cotidiano escolar. O objetivo geral foi promover ações que possibilitem aos/as professores/as o conhecimento, cultivo e consequente melhoria da qualidade de vida coerente e integradora da pessoa humana, em sua dimensão sexual, por meio de prática pedagógica que eduque para a vivência da sexualidade de forma reflexiva e crítica. O desenvolvimento do projeto deu-se através do embasamento teórico e metodológico. Por meio dos resultados da ação extensionista, reafirmamos a necessidade de a formação de professores/as tanto inicial como continuada trabalhar de forma teórica e metodológica as questões pertinentes à Educação Sexual, a fim de construir e constituir uma Educação Sexual emancipatória promovendo o aprimoramento de um olhar mais crítico acerca das informações recebidas, se constituindo como sujeito consciente do direito de ser livre para viver sua sexualidade, como também o dever de respeitar a liberdade de escolha do/a outro/a.

Palavras-chave: Educação Sexual. Sexualidades. Formação de Professores/as.

\section{SEXUAL EDUCATION AND SEXUALITIES: REFLECTIONS ABOUT EXTENSION ACTIONS IN THE TRAINING OF TEACHERS}

\begin{abstract}
This experience report discusses the extension project "Sexual education: pleasure to meet", developed during the school year 2013 and beginning of 2014, in the thematic area of education, specifically discussing the training of teachers on issues of sexuality and school everyday. The general objective was to promote actions that enable teachers to know, cultivate and consequently improve the coherent and integrating quality of life of the human person, in their sexual dimension, through a pedagogical practice that educates them to live the sexuality of reflective and critical. The development of the project was based on theoretical and methodological basis. Through the results of the extension action, we reaffirm the need for teacher training both initial and continued to work in a theoretical and methodological manner the issues pertaining to Sexual Education, in order to build and constitute an emancipatory Sexual Education promoting the improvement of a a more critical view of the information received, becoming a conscious subject of the right to be free to live their sexuality, as well as the duty to respect the freedom of choice of the other.
\end{abstract}

Keywords: Sexual Education. Sexualities. Training of Teachers.

\section{EDUCACIÓN SEXUAL Y SEXUALIDADES: REFLEXIONES SOBRE ACCIONES EXTENSIONISTAS EN LA FORMACIÓN DE PROFESORES/AS}

\section{Resumen}

Este relato de experiencia discurre sobre el proyecto de extensión "Educación sexual: placer en conocer", desarrollado durante el año escolar de 2013 e inicio de 2014, en el área temática de la educación, discutiendo específicamente la formación de profesores sobre cuestiones de la sexualidad y cotidiano escolar. El objetivo general fue promover acciones que posibiliten a los/las profesores/as el conocimiento, cultivo y consecuente mejoría de la calidad de vida coherente e integradora de la persona humana, en su dimensión sexual, por medio de práctica pedagógica que eduque para la vivencia de la sexualidad de la sexualidad forma reflexiva y crítica. El desarrollo del proyecto se dio a través del basamento teórico y metodológico. Por medio de los resultados de la acción extensionista, reafirmamos la necesidad de la formación de profesores/as tanto inicial y continuada trabajar de forma teórica y metodológica las cuestiones pertinentes a la Educación Sexual, a fin de construir y constituir una Educación Sexual emancipatoria promoviendo el perfeccionamiento de una mirada más crítica acerca de las informaciones recibidas, constituyéndose como sujeto consciente del derecho de ser libre para vivir su sexualidad, así como el deber de respetar la libertad de elección del/a otro/a.

Palabras clave: Educación Sexual. Sexualidad. Formación de Profesores/as. 
Educação sexual e sexualidades: reflexões sobre ações extensionistas na formação de professores/as

\section{INTRODUÇÃO}

Entende-se sexualidade como manifestação intrínseca do ser humano, com importância no desenvolvimento e na vida social das pessoas, pois, independente da potencialidade reprodutiva, relaciona-se com o direito ao prazer e, a saber, como exercê-la com responsabilidade. No entanto, o trabalho com Educação Sexual é incipiente, seja meio de palestras ou ações pontuais, ou ainda nem se faz presente no espaço escolar (NUNES, 2010).

Apesar de a Lei de Diretrizes e Bases da Educação Nacional - LDBEN n. ${ }^{\circ}$ 9394/96 regulamentar que é dever da família e, sobretudo, do Estado favorecer o pleno desenvolvimento do educando, além de os Parâmetros Curriculares Nacionais abordarem a temática sexualidade como tema transversal, no sentido de orientação sexual, as escolas ainda relutam em incluí-la como uma de suas preocupações pedagógicas, às vezes pela resistência de alguns/as professores/as que acham a temática incômoda e complexa. Muitos docentes acreditam que esses assuntos devem ser transmitidos por pessoa capacitada, como médico/a, enfermeiro/a, psicólogo/a, ou seja, compreendem que ainda são escassos os subsídios pedagógicos sobre tal temática (NUNES, 2010).

Além disso, toda Educação Sexual implica em reeducação da própria sexualidade. Os/as educadores/as sentem dificuldade pessoal em compreender a complexidade da sexualidade humana, por envolver posturas, tabus, crenças e valores a respeito de relacionamentos e comportamentos sexuais, requerendo olhar reflexivo sobre a própria sexualidade, dedicação e estudo.

A intenção do projeto de formação de professores/as intitulado "Educação Sexual: prazer em conhecer" foi salientar que a sexualidade é parte constitutiva do ser humano e atravessa a dinâmica das relações sociais. Neste contexto, a Educação Sexual emerge com bastante significado, dada sua relação com a própria condição humana, pois a sexualidade permeia todas as manifestações do indivíduo, do nascimento até a morte. Engloba o papel sexual desempenhado pelo ser humano, o respeito do indivíduo por si e pelo outro, as discriminações e os estereótipos atribuídos e vivenciados nos relacionamentos humanos.

A partir das ideias e contribuições de Michael Foucault falar de Educação Sexual significa falar de concepções cristalizadas no homem/mulher moderno/a sobre questões produzidas como verdade nos três últimos séculos na sociedade ocidental. Significa também falar de repressão, poder, preconceito, interdição do corpo, desejo, paixão, prazer, vida, morte, controle, gênero, pecado, violência de gênero, violência contra crianças e adolescentes, amor, orientação sexual, construção de papeis sexuais, infecções sexualmente transmissíveis - IST e atualmente 
Educação sexual e sexualidades: reflexões sobre ações extensionistas na formação de professores/as

aids; enfim, de todas as representações sociais que giram em torno dela na sociedade. Estas questões não estão fora do espaço escolar, como diz Figueiró (2006):

Se pensarmos que a finalidade maior da educação sexual é contribuir para que o educando possa viver bem a sua sexualidade, de forma saudável e feliz, e, ao mesmo tempo, contribuir para que ele esteja apto a participar da transformação social, em todas as questões ligadas direta ou indiretamente à sexualidade, podemos concluir que o professor que ensina sobre sexualidade, de forma humanizadora, está sendo um mediador de esperanças e de projetos de vida (FIGUEIRÓ, 2006, p. 17).

Educação Sexual é tema frequentemente vivenciado e discutido por alunos/as e professores/as nas escolas. Formalmente, o tema tem sido objeto de discussão nos programas de Educação Sexual ou em aulas de Ciências ou Biologia. Informalmente, nas conversas e relacionamentos entre estudantes no cotidiano da escola e nas reuniões pedagógicas dos/as docentes. $O$ interesse sobre a sexualidade no contexto escolar reforça característica multidimensional do processo ensino-aprendizagem, mostrando que o desenvolvimento cognitivo do indivíduo é estreitamente relacionado e, portanto, influenciado por seu desenvolvimento pessoal e social, no qual a sexualidade e a afetividade têm papeis fundamentais.

A Sexualidade é uma das dimensões fundamentais da condição humana, e se desenvolve e se apresenta sempre influenciada por sentimentos e valores. É um fenômeno multidimensional, não apenas psíquico, mas também biológico e sociocultural. Inerente à vida do ser humano, a sexualidade se manifesta desde o nascimento e se constrói ao longo de toda existência, nas relações interpessoais, no momento sociocultural e histórico em que estamos vivendo. Isso implica afirmar que nossa sexualidade é construída socialmente, dando importância à educação voltada para princípios, como respeito a si mesmo, ao outro, à diversidade sexual, ou seja, viver a sexualidade com consciência e responsabilidade.

Nesse sentido, é preciso estimular o reconhecimento de limites da formação docente e ampliação das reflexões que ajudem os/as educadores/as a tomarem suas decisões de direção, no que concerne ao trabalho com sexualidade no cotidiano escolar. Essa proposta de formação continuada vem ao encontro de uma demanda real vivenciada por meio dos relatos de situações dos estágios supervisionados, que demonstra dificuldade docente de abordar questões sobre sexualidade no cotidiano escolar. Consideramos essa dificuldade "natural", uma vez que o tema mobiliza as mais variadas questões advindas da cultura, ciência, religião, e muitas vezes da falta de informação no próprio curso de formação inicial ou ausência dessa temática na formação continuada.

Objetivamos sensibilizar, abrir espaço para essas questões cotidianas do mundo escolar, apontar possibilidades de trabalho coletivo, a fim de amenizar o impacto dessas questões em suas 
Educação sexual e sexualidades: reflexões sobre ações extensionistas na formação de professores/as

relações de trabalho. Ao trabalhar com formação de professores/as, esperamos que eles/as possibilitem nos espaços escolares onde atuam uma postura de escuta sensível aos/às estudantes, buscando entender o que para eles/as constitui conflito, suas fantasias, medos, esperanças e a qualidade das informações no que diz respeito à temática da sexualidade. Assim, exercitam-se alternativas para que se posicionem melhor em relação à sua sexualidade, para que construam projetos de vida, exerçam sua cidadania elaborando e executando ações a partir do que foi aprendido no ambiente escolar.

Ao abordar o tema Educação Sexual na escola faz-se necessário um apanhado sobre visões e elaborações sociais, culturais, historicamente construídas, acerca das sexualidades. Noções e concepções de sexualidades durante seu processo histórico-cultural são arraigadas de certas "verdades" que orientam a prática do/a educador/a, mas que precisam ser desconstruídas e ressignificadas.

Segundo Camargo e Ribeiro (1999), o espaço familiar e a escola se transformaram em ambientes de formação dos/as filhos/as por meio da educação de seus corpos e, principalmente, de uma educação do sexo. Essa educação passava ou ainda passa pelo não dito, pelo falar o mínimo possível. Neste sentido, compreendia-se que quanto menos se tocasse no assunto, seria mais protegido e mais fácil de controlar. Essa ligação entre sexualidade e vergonha foi tomando maior conotação. Alguns estudos sobre a sexualidade infantil surgiram, porém eram considerados sinônimo de patologia. Nesse ambiente de repressão, a sexualidade infantil foi colocada para trás, considerando que a construção histórica sobre a criança como ser puro e desprovido de sexualidade. Diante disso, os estudos de Freud representavam uma ruptura sobre as questões da sexualidade e principalmente no aspecto infantil (NUNES, 1987).

Nessa conjuntura, Guimarães (1995) define Educação Sexual de duas maneiras: Educação Sexual informal: interação do/a educando/a em contato com a família e sociedade; Educação Sexual formal: trabalho escolar, planejado, sistemático e contínuo que tem por objetivo ir além das informações sobre aspectos biológicos, abordando assuntos que dizem respeito às sexualidades, como: aborto, IST, namoro, violência de gênero, violência sexual de crianças e adolescentes, sexualidade e internet, entre outros.

Em consonância com os pressupostos até agora mencionados, Camargo e Ribeiro (1999) concebem Educação Sexual como processo iniciado antes mesmo do nascimento e que se prossegue pela vida afora. Neste sentido, a Educação Sexual contempla informações recebidas ao longo da vida, o que para alguns/as autores/as este processo é conceitualizado como informal, porém, esse, não é desarticulado de toda uma conjuntura social-cultural, política e religiosa na construção de conceitos, procedimentos e atitudes diante da própria sexualidade. 
Educação sexual e sexualidades: reflexões sobre ações extensionistas na formação de professores/as

Segundo Figueirêdo Netto (2006) a Educação Sexual deve ser perpassada pelo modelo relacional, em que os fundamentos filosóficos do personalismo e os fundamentos teóricos da Sexologia se façam presentes. A autora acredita nesta possibilidade de trabalho, na qual o modelo relacional torna-se centro orientador da postura pedagógica que compreende a sexualidade como uma das dimensões integradora do ser humano.

Acrescente-se nessa reflexão que nos dias atuais é muito difícil falar sobre sexo e a sexualidade, pois, mesmo sendo assunto estampado, presente em programas de televisão, letras de músicas e nas redes sociais, presenciamos uma sexualidade exibicionista, mecânica, quantitativa, genital impessoal que faz parte da nossa realidade (NUNES, 2010). Tendo em vista o que foi mencionado, o Parâmetro Curricular Nacional de Orientação Sexual propõe:

\footnotetext{
[...] que a orientação sexual oferecida pela escola, aborde as repercussões de todas as mensagens transmitidas pela mídia, pela família e pela sociedade, com as crianças e os jovens. Trata-se de preencher lacunas nas informações que a criança já possui e, principalmente, criar a possibilidade de formar opinião a respeito do que lhe é ou foi apresentado. A escola ao propiciar informações atualizadas do ponto de vista científico e explicitar os diversos valores associados à sexualidade e aos comportamentos sexuais existentes na sociedade, possibilita ao aluno desenvolver atitudes coerentes com os valores que ele próprio elegeu como seus. (BRASIL, 1998, p. 83).
}

Isso posto, cabe à escola ensinar, informar e promover informação e discussão sobre sexualidades. Fazendo isso, proporcionará ao/a educando/a maior conhecimento do seu corpo e de suas vontades. A discussão de questões relativas às sexualidades deve fazer parte do cotidiano escolar, pois promove conhecimento integral e remete os/as educandos/as à reflexão.

Seguindo essa premissa, Egypto (2003) afirma:

\begin{abstract}
A escola é um lugar onde se está produzindo diálogo e reflexão. É, portanto, um espaço privilegiado para discutir a sexualidade com crianças e adolescentes. $\mathrm{Na}$ medida em que a escola se nega ou não consegue se capacitar para poder dar conta dessa responsabilidade, ela reforça a idéia que de que a sexualidade não faz parte do conhecimento humano (EGYPTO, 2003, p.16).
\end{abstract}

Neste sentido, Figueirêdo Netto (2006) afirma que a escola tem responsabilidade e obrigação de oferecer formação integral aos/as educandos/as. Para essa autora, escola se constitui enquanto agente informador e formador por natureza, local idôneo da promoção do conhecimento socializado e de cooperação entre família e instituição de ensino.

Neste momento, reiteramos que a escola pode possibilitar aos/as educandos/as novas possibilidades de entendimento e compreensão da sexualidade, que deve ser diferente daquela oferecida pela mídia ou conhecimentos equivocados. Egypto (2003, p.16) destaca: “A escola é um lugar onde se está discutindo conhecimento, onde se está produzindo diálogo e reflexão. É, portanto, um espaço privilegiado para discutir a sexualidade com crianças e adolescentes". 
Educação sexual e sexualidades: reflexões sobre ações extensionistas na formação de professores/as

Diante disso, quando a escola discute sobre as questões das sexualidades, está promovendo ao mesmo tempo saúde, discussão de valores, conhecimento do corpo, debate sobre prazer, excitação, desejo e outros temas. Vale ressaltar que muitas escolas trabalham a dimensão biológica do organismo humano (órgãos, aparelhos, sistemas) e dizem estar trabalhando Educação Sexual. O trabalho com sexualidade poderá abordar temas polêmicos, tais como: aborto, excitação, masturbação, homossexualidade, virgindade, casamento, divórcio, traição e outros. Este vai além das aulas de anatomia, fisiologia e prevenção de doenças (NUNES, 1987; 2010).

$\mathrm{Na}$ atualidade, a discussão da necessidade da Educação Sexual na escola deveria estar superada, uma vez que as consequências das ausências dessas informações sobre a sexualidade podem ser claramente sentidas. $\mathrm{Na}$ atual sociedade, a liberdade de expressão é exercida quase na sua totalidade e a sexualidade é mostrada na televisão e em folhetins de forma fragmentada. Assim, o tema precisa ser tratado de forma sistemática, consciente e responsável na escola (CAMARGO; RIBEIRO, 1999, p.40).

Dessa forma, apresentamos a seguir o quadro com visão geral do projeto "Educação Sexual: prazer em conhecer", e a seguir explicitaremos como o mesmo foi desenvolvido.

\begin{tabular}{|c|c|c|}
\hline \multicolumn{3}{|r|}{ Projeto "Educação Sexual: prazer em conhecer" } \\
\hline \multirow[t]{2}{*}{ Objetivos } & 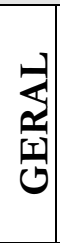 & $\begin{array}{l}\checkmark \text { Promover ações que possibilitem aos/às professores/as } \\
\text { conhecimento, cultivo e consequente melhoria da qualidade de vida } \\
\text { coerente e integradora da pessoa humana, em sua dimensão sexual, por } \\
\text { meio de prática pedagógica que eduque para vivência da sexualidade de } \\
\text { forma reflexiva e crítica. }\end{array}$ \\
\hline & 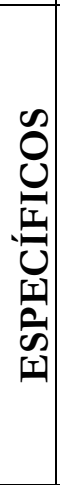 & $\begin{array}{l}\checkmark \text { Ressignificar concepção de sexualidade. } \\
\checkmark \text { Estabelecer relação entre sexualidade e gênero, sexualidade e saúde } \\
\text { no contexto escolar. } \\
\checkmark \text { Promover processo de personalização por meio da clarificação de } \\
\text { conhecimentos e valores no que diz respeito à Educação Sexual. } \\
\checkmark \text { Analisar manifestações das sexualidades no contexto escolar. } \\
\checkmark \text { Discutir sexualidade como elemento constitutivo da pessoa } \\
\text { humana. } \\
\checkmark \text { Contribuir para formação de professores/as capazes de analisar } \\
\text { questões relativas às sexualidades no contexto escolar. }\end{array}$ \\
\hline Conteúdos & & $\begin{array}{ll}\checkmark & \text { Compreendendo a história da Educação Sexual. } \\
\checkmark & \text { Sexualidade humana e saúde sexual. } \\
\checkmark & \text { Necessidade da Educação Sexual nas escolas. } \\
\checkmark & \text { Processo de Sexualização da pessoa. } \\
\checkmark & \text { Questões de gênero no ambiente escolar. } \\
\checkmark & \text { Preconceito e homofobia na escola. } \\
\checkmark & \text { Sugestões de atividades para trabalhar educação sexual na escola. }\end{array}$ \\
\hline
\end{tabular}


Educação sexual e sexualidades: reflexões sobre ações extensionistas na formação de professores/as

\begin{tabular}{|l|l|}
\hline Procedimentos & $\checkmark$ Rodas de discussões, exibição de trechos de filmes, leituras \\
Metodológicos & $\begin{array}{l}\checkmark \text { sistematizadas de textos, estudos de casos, dramatizações, uso de } \\
\text { músicas, produção de textos com imagens e desenhos, colagens, aulas } \\
\text { expositivas participadas, dinâmicas de grupos, confecção de painéis e } \\
\text { cartazes e outros. }\end{array}$ \\
\hline Recursos & $\begin{array}{l}\checkmark \text { Trabalhamos com recursos próprios e tivemos como material de } \\
\text { apoio: papel ofício, cartolinas, bexigas, lápis de cor, pincel atômico, } \\
\text { CDs, aparelho de som, tintas, pinceis, colas, tesouras, textos } \\
\text { xerografados, computador, data show e outros. }\end{array}$ \\
\hline Avaliação & $\begin{array}{l}\checkmark \text { A avaliação foi constante através de depoimentos no final de cada } \\
\text { dia, em que os/as participantes responderam a questões quanto ao } \\
\text { desenvolvimento das atividades e se os objetivos foram alcançados. } \\
\text { Além disso, foram observados os seguintes critérios: participação, } \\
\text { interesse e envolvimento nas atividades propostas. }\end{array}$ \\
\hline
\end{tabular}

Em consonância aos pressupostos anunciados no projeto "Educação Sexual: prazer em conhecer", defendemos a constituição de uma proposta de formação docente sob a perspectiva da Educação Sexual Emancipadora (NUNES, 1987; 2010). A mesma possibilitará aos/as estudantes refletir sobre questões relacionadas à sexualidade. Fazendo isto, estaremos promovendo o aprimoramento de um olhar mais crítico acerca das informações recebidas informalmente. Nesse sentido, a formação de professores/as torna-se essencial para desenvolvimento deste trabalho e não há lugar melhor para fazer isso do que a escola, pois lá crianças e jovens passam a maior parte do seu tempo, produzem conhecimento e manifestam desejo de saber.

\section{MATERIAIS E MÉTODOS}

Escolher a trilha metodológica de um estudo ou trabalho de intervenção não é tarefa fácil nem simples. Requer conhecimento da complexidade do objeto, pois este diz por onde o pesquisador deverá caminhar. Ao trilhar por vias demandadas pelo objeto, o pesquisador pode escolher a forma de enxergar este objeto a partir de suas concepções de mundo, de ser humano, a forma como o conhecimento se constrói e suas relações com a sociedade.

Segundo Moreira e Caleffe (2008), a maneira como pesquisadores/as adotam determinados pressupostos corroboram questões mais amplas, de cunho ontológico, que dão origem aos pressupostos epistemológicos e que terão implicações metodológicas para realização da coleta de dados e informações na ação.

Ao compreender a metodologia como conjunto mais amplo, em que estão inseridos os métodos, as técnicas e os procedimentos investigativos, o/a pesquisador/a elucida o processo de 
Educação sexual e sexualidades: reflexões sobre ações extensionistas na formação de professores/as

pesquisa. Ele/a aprimora, pois encara "a reflexão sobre os métodos e suas relações com as técnicas, no contexto das epistemologias que os fundam" (GAMBOA, 2007, p.66).

O projeto em questão aconteceu durante o ano letivo de 2013 e 2014, com carga horária total da ação extensionista de seiscentos e quarenta horas, distribuídas nos dois anos mencionados por meio de atividades como: reuniões de planejamento, estudo sistemático dos assuntos abordados, aplicação e análise de questionário, produção de relatórios, oficinas sobre os conteúdos mencionados no quadro anterior. Contamos com equipe de dez integrantes (três professoras colaboradoras, dois estudantes bolsistas de extensão e cinco estudantes voluntários/as), além de um coordenador geral do projeto. Tivemos ainda como participantes do projeto trinta e quatro pessoas (vinte e seis mulheres e oito homens), entre professores/as da cidade de Mamanguape - PB e Rio Tinto-PB, além de estudantes das licenciaturas (Pedagogia, Ciência da Computação e Matemática) do Centro de Ciências Aplicadas e Educação da Universidade Federal da Paraíba, Campus IV - Litoral Norte. Os participantes do projeto buscaram participar espontaneamente do projeto devido às informações divulgadas pelo Campus da Universidade e em escolas da região no momento em que aplicávamos os questionários.

Inicialmente foi feito estudo teórico e metodológico sobre a temática a ser desenvolvida, coordenada pelo professor responsável pelo projeto com os demais estudantes envolvidos durante o primeiro semestre do ano de 2013. Esses estudos e sistematizações nos permitiram organizar ideias e conceitos sobre a temática da Educação Sexual. Os encontros de formação do grupo aconteciam a cada quinze dias no Centro de Ciências Aplicadas e Educação da UFPB, no Campus IV, com estudos e cronograma de atividades previamente definidos. Em seguida, no segundo semestre do ano de 2013, elaboramos questionário com questões abertas e fechadas, com objetivo de conhecer percepções acerca da Educação Sexual dos/as professores/as do Ensino Fundamental da rede pública de Mamanguape - PB e Rio Tinto - PB.

Ao sistematizarmos análises dos questionários aplicados, constatamos que a frequência com que se discutem os assuntos referentes à Educação Sexual na escola é pouca, ou não se discute. Porém, todos os/as respondentes concordaram sobre a importância da escola e dos/as professores/as abordarem temáticas das sexualidades e também mencionaram a necessidade de cursos de formação que abordassem essa temática.

Ficou também evidente quando perguntamos sobre quais assuntos deveriam ser abordados na Educação Sexual no contexto da escola e os temas resumiam-se a: infecções sexualmente transmissíveis - IST, aids, gravidez e sistema reprodutor. Assim, percebemos também falta de conhecimento e formação sobre aspectos mais amplos das Sexualidades e da Educação Sexual, 
Educação sexual e sexualidades: reflexões sobre ações extensionistas na formação de professores/as

como: relacionamento, amor, paixão, ficar, violência sexual contra crianças e adolescentes, violência de gênero e outros.

Perguntamos ainda por meio do questionário aplicado aos/as professores/as sobre alguma situação vivenciada na escola ou na sala de aula com relação à sexualidade. Eles foram enfáticos ao mencionar situações como: palavrões e desenhos nas paredes da sala ou nas carteiras, alunos tocando nas suas genitálias, vendo filmes pornôs pelo celular no banheiro, preconceitos, homofobia e algumas perguntas que não sabiam como responder aos/as estudantes, pois queiramos ou não a sexualidade está la, na sala de aula, nos pátios da escola, nos banheiros, na piadas e outros espaços.

A partir do levantamento de informações, organizamos nossas oficinas para o segundo semestre letivo do ano de 2013 e o início do ano de 2014 sobre os assuntos já mencionados no quadro apresentado anteriormente. Essas oficinas geralmente eram iniciadas com alguma dinâmica de grupo, uso de vídeo ou situação problema, texto reflexivo sobre a temática do dia, leitura de reportagens sobre o assunto da oficina, exposição participada com o grupo, trabalho em grupo como construção de cartazes, mapas conceituais, uso de imagens, desenhos, dramatizações e painéis. Em seguida o grupo socializava a produção da atividade, tínhamos também roda de discussão sobre os trabalhos realizados durante a oficina e no final de cada oficina fazíamos a avaliação do encontro, essa podendo ser oral, escrita ou gestual.

Um procedimento metodológico adotado nas oficinas pedagógicas foi o trabalho com trechos de filmes e documentários. Esse recurso foi bastante interessante e incentivador de efervescente debate entre os participantes durante as rodas de discussão. Utilizamos trechos do filme "Orações para Bob" (em português) e o vídeo "boneca na mochila". Esses filmes estão disponíveis na internet para serem consultados e utilizados a partir dos objetivos de cada trabalho.

Outro material utilizado durante nossas oficinas foram várias músicas para trabalharmos as questões de gênero no ambiente escolar. Buscamos trazer para o debate as letras das músicas mais ouvidas e tocadas na região. Fizemos audição das músicas e logo em seguida, organizados em grupos, os/as participantes analisaram as letras das músicas. Algumas das letras das músicas trabalhadas foram: Menina - Netinho; Xote das meninas - Luiz Gonzaga; Ai que saudade da Amélia - Mario Lago; Mulheres de Atenas - Chico Buarque; Descontruindo Amélia - Pitty; Porque homem não chora - Pablo; e Um homem também chora - Gonzaguinha.

Não poderíamos deixar de ressaltar importância de se trabalhar com estudos de caso e dramatizações de situações que poderiam acontecer no contexto escolar com participantes do projeto. Os estudos de caso constituíam-se em situações nas quais o grupo resolveria aquela 
Educação sexual e sexualidades: reflexões sobre ações extensionistas na formação de professores/as

situação fictícia. Quanto às dramatizações, a partir da resolução do caso, cada grupo encenava aquela circunstância estudada e discutida.

Assim, o desenvolvimento do projeto "Educação Sexual: prazer em conhecer" deu-se por meio da intersecção entre teoria e prática a todo o momento, propiciando embasamento teórico e metodológico, reflexão crítica, autoconhecimento, respeito ao outro, responsabilidade e comprometimento, condições necessárias ao trabalho do/a educador/a.

\section{ALGUNS ACHADOS DO PROJETO: REFLEXÃO E PRÁTICA EM PARCERIA}

Durante a execução do projeto ao avaliarmos nossas ações nas rodas de discussão com os/as participantes os objetivos propostos, podemos concluir que obtivemos êxito nas atividades que desenvolvemos, como por exemplo: a ressignificação da concepção de sexualidade, possibilidades para abordar as questões da sexualidade no contexto escolar dos/as professores/as envolvidos das cidades de Mamanguape e Rio Tinto. Quanto dos/as estudantes das licenciaturas, a ênfase na conexão entre sexualidade, desenvolvimento pessoal, relação interpessoal e sociedade, o estabelecimento da relação entre sexualidade e gênero, sexualidade e saúde e o cotidiano escolar foi bastante relevante para a atuação docente. Isso ficou evidente em depoimentos dos/as participantes do curso de formação, por meio de falas como:

Foi muito bom participar do projeto, pois agora posso ter mais clareza de como abordar os assuntos da sexualidade na minha sala de aula (professora participante do projeto).

Se eu não tivesse feito a minha inscrição e arrumado um tempo para participar desse projeto iria terminar o curso de Pedagogia e não saberia como trabalhar esses assuntos da sexualidade das crianças na sala de aula. Foi muito importante! (Estudante do curso de Pedagogia participante do projeto).

Eu tinha muita vergonha de falar sobre esses assuntos na sala de aula. Acho que porque não estudei sobre isso. Agora melhorou um pouco. Sei que preciso estudar mais. Porém, aqui me possibilitou ver com outros olhos esses assuntos (professora participante do projeto).

Diante disso, depreendemos o quanto o projeto possibilitou aos/as participantes perceber e pensar sobre as questões das sexualidades presentes no cotidiano escolar. Entretanto, vale ressaltarmos que ações de formação continuada são sempre necessárias, e uma ação como essa desenvolvida não é suficiente para sanar todas as lacunas da formação docente, porém é um início de um longo processo formativo. 
Educação sexual e sexualidades: reflexões sobre ações extensionistas na formação de professores/as

Nessa conjuntura, as ações desenvolvidas no projeto permitiram aos seus envolvidos e às envolvidas refletir e reconstruir os seus conceitos sobre as sexualidades em prol de uma prática pedagógica voltada para a formação cidadã. São aqui oportunas às palavras de Biancon (2005) ao mencionar que:

Acreditamos que a Educação Sexual, ao lado de outros temas propostos nos Parâmetros Curriculares Nacionais, ajude na formação da cidadania, que é uma das principais preocupações da escola. As intervenções pedagógicas da Educação Sexual na escola podem favorecer a reflexão sobre a própria sexualidade, desenvolvendo os temas polêmicos e favorecendo ampla liberdade de expressão em ambiente agasalhador, vindo promover bem-estar sexual e aperfeiçoando a cidadania (BIANCON, 2005, p. 21).

Em alinhamento ao que já mencionamos, salientamos ainda como resultados positivos alcançados no projeto a ênfase no papel do/a educador/a sexual, possibilitando ao indivíduo tornar-se pessoa consciente, responsável e autônoma, as discussões sobre sexualidade como elemento constitutivo da pessoa e a contribuição para formação de profissionais capazes de analisar questões relativas às sexualidades e utilização de procedimentos metodológicos para tratar o tema em sala de aula.

Acresce nessa reflexão quando Louro (1999, p. 80-81) ressalta que as discussões sobre as sexualidades no ambiente escolar são indispensáveis, pois a [...] "escola não apenas reproduz ou reflete as concepções de gênero e sexualidade que circulam na sociedade, mas ela própria as produz".

Percebemos também que o projeto permitiu ainda a integração acadêmica com ensino e pesquisa, pois possibilitou mais demanda para oferecimento da disciplina Educação Sexual na graduação nos cursos de Licenciaturas nos semestres posteriores, além de promover durante o período da ação extensionista a integração entre áreas do conhecimento, devido ao envolvimento de professores/as de área do curso de Pedagogia, Psicologia, Farmácia com a temática das sexualidades e Educação Sexual.

Durante e após o encerramento do projeto, vale ressaltar outros resultados no que diz respeito à publicação de artigos com apresentação em forma de comunicação oral pelos/as estudantes envolvidos/as (bolsistas e voluntários/as), em eventos internacionais e nacionais. Tivemos ainda a produção de projetos de pesquisas e monografias sobre temática da Educação Sexual, envolvendo questões da formação de professores/as, do cotidiano escolar, da sexualidade de pessoas com síndrome de Down e o processo de escolarização de travesti. 
Educação sexual e sexualidades: reflexões sobre ações extensionistas na formação de professores/as

Não poderíamos deixar de mencionar que durante a realização da ação extensionista apresentamos alguns pontos a serem repensados para outra edição do projeto. Foram situações como: a falta de recursos financeiros para o projeto, os atrasos de alguns participantes para as oficinas pedagógicas e a dificuldades dos/as professores/as participar das oficinas devido à necessidade de liberação da escola. Entretanto, acreditamos que com essas ações intervencionistas, no que diz respeito à formação de professores/as sobre a Educação Sexual foi possível reconhecer, nos/as participantes a vontade em aprender, refletir, construir procedimentos teóricos, metodológicos e acima de tudo, promoverem mudanças em prol de uma sociedade mais justa, igualitária e plural.

Nesse eixo interpretativo, são oportunas as palavras de Alevato (2012):

Educação sexual não é uma 'disciplina' à parte. É formação humana que se relaciona não apenas com a escolha do parceiro ou com a obediência às determinações de 'parâmetros curriculares'. Relaciona-se com todas as esferas da vida. Relaciona-se com a organização da sociedade, às políticas da subjetividade, às relações de poder e até ao sofrimento vivido por aqueles/as que ousam (ou não ousam, já que também sofrem) ir além dos artefatos materiais e simbólicos que identificam e enquadram seu gênero (ALEVATO, 2012 p.84).

Assim sendo, ratificamos o quanto o projeto "Educação Sexual: prazer em conhecer" gerou impacto social nos atores e atrizes envolvidas nessa ação extensionista no que diz respeito a entender e refletir sobre as sexualidades e suas questões que se fazem presentes e permeiam todo o cotidiano escolar.

\section{CONSIDERAÇÕES FINAIS}

Diante das reflexões expostas e em consonância com os nossos objetivos elencados no decorrer desse texto acerca do projeto "Educação Sexual: prazer em conhecer", reafirmamos que a formação de professores/as também deve trabalhar de forma teórica e metodológica questões inerentes à Educação Sexual. Enfatizamos que os/as professores/as e a escola precisam conhecer de forma fundamentada as questões das sexualidades, a fim de promover construção e constituição de uma Educação Sexual emancipatória.

Todos/as os/as professores/as que participaram respondendo aos questionários concordaram sobre a importância e a necessidade da Educação Sexual na escola e no seu processo de formação docente, seja inicial ou continuada. Salientaram ainda que somente com ações pontuais não estarão promovendo Educação Sexual na qual todos e todas tenham direitos e sejam respeitados/as. 
Educação sexual e sexualidades: reflexões sobre ações extensionistas na formação de professores/as

Assim, esperamos que as provocações iniciais aqui mencionadas e socializadas, no âmbito das ações extensionistas do Centro de Ciências Aplicadas e Educação da UFPB, sejam excitantes a ponto de criarem outras possibilidades de formação de professores/as no contexto da Educação Sexual Emancipatória.

\section{REFERÊNCIAS}

ALEVATO, Hilda. Nexus \& sexus: (trans) formações docentes. In: REIS, Maria Amélia de Souza; ALEVATO, Hilda (Orgs.). Nexus \& sexus: perspectivas instituintes. Petrópolis, RJ: DP et alii; Rio de Janeiro: FAPERJ, 2012, p. 53-87.

BIANCON, Mateus Luiz. A Educação sexual na escola e as tendências da prática pedagógica dos professores. Londrina, 2005, Dissertação (Mestrado em Ensino de Ciências e Educação Matemática) - Universidade Estadual de Londrina, 2005.

BRASIL. Lei de Diretrizes e Bases da Educação Nacional no 9.394, de 20 de dezembro de 1996. Brasília, DF, MEC, 1996.

BRASIL. Ministério da Educação e do Desporto. Parâmetros curriculares nacionais: pluralidade cultural e orientação sexual. Secretaria de Educação Fundamental. Brasília: MEC/SEF, 1998.

CAMARGO, Ana Maria Facciolli de; RIBEIRO, Cláudia. Sexualidades e infâncias: a sexualidade como um tema transversal. São Paulo: Moderna; Campinas, SP: Editora da Universidade de Campinas, 1999.

EGYPTO, Antônio Carlos (org.). Orientação sexual na escola: um projeto apaixonante. São Paulo: Cortez, 2003.

FIGUEIREADO NETTO, Jerusa Maria. Sexualidade e trabalho. In: OLIVEIRA, Maria Helena Alcântara de (Org.). Trabalho e deficiência Mental: perspectivas atuais. Brasília: Dupligráfica Editora, 2006. p.93-110.

FIGUEIRÓ, Mary Neide Damico. Formação de educadores sexuais: adiar não é mais possível. Campinas, SP: Mercado de Letras; Londrina, PR: EDUEL, 2006.

GAMBOA, Silvio Sánchez. Tendências epistemológicas: dos tecnicismos e outros "ismos" aos paradigmas científicos. In: SANTOS FILHO, José Camilo dos; GAMBOA, Silvio Sánchez (Org.). Pesquisa educacional: quantidade - qualidade. 6. ed. São Paulo: Cortez, 2007, p. 60-83.

GUIMARAES, Isaura. Educação Sexual na escola: mito e realidade. Campinas, SP: Mercado das Letras, 1995.

LOURO, Guacira Lopes. Sexualidade, gênero e educação: uma perspectiva pós-estruturalista. 3.ed. Petrópolis, RJ: Vozes, 1999.

MOREIRA, Herivelto; CALEFFE, Luiz Gonzaga. Metodologia da pesquisa para o professor pesquisador. 2. ed. Rio de Janeiro: Lamparina, 2008. 
Educação sexual e sexualidades: reflexões sobre ações extensionistas na formação de professores/as

NUNES, César Aparecido. Desvendado a sexualidade. Campinas, SP: Papirus, 1987.

NUNES, César Aparecido. Educação Sexual: uma educação emancipatória. DVD. São Paulo: Paulus, 2010. 